\title{
Apresentação de pacientes: Clérambault, mestre de Lacan
}

\author{
Cristiana Miranda Ramos Ferreira*1 \\ Jésus Santiago*2
}

A apresentação de pacientes é um dispositivo tradicional da psiquiatria, que foi introduzido na psicanálise por Lacan. Este artigo analisa as influências que Lacan recebeu de seu mestre, Clérambault, ressaltando os pontos de continuidade e as alterações produzidas, na prática da apresentação, a partir de sua operação pelo discurso do analista.

Palavras-chave: Apresentação de paciente, psicanálise, Lacan, Clérambault

${ }^{* 1}$ Faculdade FEAD (Belo Horizonte, MG, Br)

${ }^{* 2}$ Universidade Federal de Minas Gerais - UFMG (Belo Horizonte, MG, Br) 
A apresentação de pacientes faz parte da tradição psiquiátrica desde o início do século XIX. Utilizada ao longo de toda a psiquiatria clássica, de Esquirol (1817) a Clérambault (1934), ${ }^{1}$ a apresentação se sustentava na lógica do 'Interrogatório', prática que tinha na fala do paciente sua principal via de acesso e apreensão da loucura. No interrogatório, o médico confrontava a verdade delirante do paciente com a realidade, de forma a desestabilizar suas crenças e provocar-lhe uma crise, presentificando assim, seus fenômenos e sintomas. Além de favorecer a elaboração do diagnóstico e prognóstico de um caso em particular, o interrogatório tinha também extrema importância para a psiquiatria de uma maneira geral, visto que seu caráter investigativo viabilizava a constituição do saber psiquiátrico, ainda em construção. A apresentação de pacientes, como era conhecida a realização pública do interrogatório, se efetivava, portanto, na articulação entre a pesquisa, a clínica e o ensino. Apesar de seu amplo uso e eficácia, isso não parece ter suscitado maiores questionamentos. Com raras exceções, quase não se encontra, ao longo de todo este período, artigos exclusivamente dedicados a elaborações, seja sobre as técnicas e estratégias da apresentação, seja sobre os efeitos produzidos sobre o paciente. Acerca do tema, o que se tem são referências casuais, intuídas nas entrelinhas das exposições teóricas e, eventualmente, em algum relato de caso, o que também não era comum na época.

Já no início do século XX, embora continue inexistindo elaborações sobre essa prática, encontraremos algumas publicações como, por exemplo, de Kraepelin (1856-1925) e Clérambault (1856-1925), nas quais figuram preciosos relatos de apresentações com comentários do paciente, ou sobre ele, e até mesmo algum fragmento do diálogo entre médico e paciente.

Mas é somente a partir da segunda metade do século XX, por volta de 1960 , que começaremos a encontrar alguns textos dedicados exclusivamente a pensar essa prática. Todavia, estes textos têm um caráter curioso, pois em sua maior parte, referem-se especificamente às apresentações de um mesmo apresentador: Lacan. São artigos de seus alunos e analisantes que, sob o impacto produzido por estas apresentações, ora tentam esclarecer as diferenças das apresentações como praticadas por Lacan das demais apresentações, ora tentam descrever seus

${ }^{1}$ Sobre o tema cf. Foucault (2006), Ferreira (2006, 2013). 
efeitos de transmissão (Leguil, 1993, 1998; Miller, 1996; Laurent, 1989). A estes escritos somam-se os artigos contemporâneos, que têm se multiplicado nos últimos anos, interessados em não apenas relatar os efeitos clínicos produzidos a partir das apresentações, como também elaborações acerca dos fundamentos teóricos e clínicos, que visam esclarecer o que viabiliza que tais efeitos sejam produzidos.

Alguns desses escritos interrogam porque Lacan fez uso dessa prática; afinal, no momento em que ele se formava psiquiatra, a prática de apresentação já não era mais a mesma do período clássico. Ao contrário, esta sofria as influências de uma psiquiatria "biologicista", perspectiva ascendente desde as primeiras décadas do século XX, que em lugar do caráter investigativo que marcara a psiquiatria clássica, se caracterizava por uma perspectiva reducionista, mais focada nos efeitos fisiológicos de suas intervenções no corpo, portanto, pouco interessada nos detalhes do caso. Tal enfoque repercutiu sobre a prática da apresentação, centrando seu interesse na dimensão de ensino, sendo a participação do paciente reduzida à função de ilustrar a disciplina estudada.

Contudo, Lacan teve como mestre, Clérambault, considerado "o último e mais brilhante dos clássicos" (Bercherie, 1980, p. 251, citado por Girard, 1993, p. 10). Nossa hipótese é que Lacan teve, com Clérambault, a oportunidade de presenciar apresentações de pacientes realizadas sob a forma clássica, afinal Clérambault sustentava, em suas apresentações, o mesmo vigor e caráter investigativo que caracterizara o interrogatório clássico, praticado por seus antecessores.

\section{O estilo do mestre}

Clérambault acreditava na organogênese da loucura. Contudo, sem acesso à lesão orgânica, ele tomou justamente o discurso do paciente como corte histológico passível de colocar à mostra os mecanismos de formação da psicose (Girard, 1993). Clérambault se mantinha fiel à ideia de que era pelo relato do paciente e pela observação cada vez mais precisa que se poderia aceder à compreensão dos fenômenos psicopatológicos, assim como às provas da loucura.

Embora Clérambault seguisse a tradição clássica, é importante ressaltar que há particularidades, tanto em seu entendimento da psicose quanto em seu objetivo com o interrogatório, diferenças que o fizeram se destacar de seus antecessores. Como elemento fundamental, que incidiu tanto sobre sua produção teórica quanto sobre sua forma de realizar as apresentações de pacientes, devemos salientar a especificidade de seu trabalho - Clérambault era chefe da Enfermaria Especial de Alienados da Prefeitura de Polícia, local para onde eram conduzidos todos aqueles que perturbavam a ordem pública: criminosos, prostitutas, vagabundos e também os alienados. Era função de Clérambault observar, diagnosticar e decidir o encaminhamento dos 
pacientes, separando os alienados dos demais pacientes, visto que esses deveriam ser conduzidos, não para o sistema judiciário, mas para o manicômio.

$\mathrm{O}$ volume de pacientes e o polimorfismo psicopatológico dessa clientela que passava pela Enfermaria Especial serviram a Clérambault como um verdadeiro observatório. Esse aspecto, aliado ao seu estilo observador, minucioso e detalhista, e ainda à liberdade de poder investigar sem se ocupar do tratamento, permitiram a Clérambault dar valiosas contribuições à psiquiatria, como, por exemplo, a descrição dos delírios tóxicos, da folie a deux, da síndrome erotomaníaca, da síndrome do automatismo mental, entre outros. Todavia era um trabalho que exigia grande sensibilidade e perícia, pois tratavam-se de casos cuja sintomatologia discreta dificultava um diagnóstico claro. De fato, a Enfermaria Especial lhe proporcionou o acesso às psicoses em um estado pouco comum para a maioria dos psiquiatras - as psicoses não desencadeadas. Dessa experiência, Clérambault pôde perceber que certos fenômenos discretos, sutis, podiam subsistir durante muitos anos, sem que se deflagrasse uma psicose. Clérambault pôde assim distinguir a psicose, enquanto base, núcleo da doença, de seus fenômenos, como os delírios e alucinações, considerados por ele como sendo secundários. Essa perspectiva o levou a deslocar o foco de seu interesse: dos fenômenos mais evidentes e exuberantes para os mecanismos geradores das psicoses. Essa investigação, ele a fará em torno de dois grandes polos - as psicoses alucinatórias como base no automatismo mental por um lado, e as psicoses paranoicas ideoafetivas por outro.

No caso das psicoses alucinatórias, considerava-as como uma doença orgânica, cuja causa seria um "processo histológico, irritativo de progressão em algum modo serpeginosa" (Clérambault, 2004, p. 114) ou, como esclarece Bercherie (2004), de progressão lenta, consequência de antigas infecções ou transtornos endócrinos. Dessa forma, as construções delirantes, por exemplo, eram consideradas como sendo uma reação imaginativa de ajuste e integração do intelecto, visando sistematizar o impacto do processo orgânico sobre o sujeito (Bercherie, 2004). Assim, em lugar de provocar a crise para presentificar os sintomas, como faziam seus colegas clássicos, Clérambault procurava detectar através da fala do paciente, os fenômenos iniciais, sutis, discretos. Nestes sintomas, os quais agrupou sob a denominação de Síndrome do Automatismo Mental, Clérambault destacava a maneira brusca, estrangeira, mecânica e parasitária, com que estes irrompiam na consciência da pessoa determinando a cisão no Eu. Para Clérambault, o caráter anidéico (abstrato, marcado pela ausência de organização temática) e a maneira intrusiva, externa, automática, com que estes se impunham à consciência, independente da intencionalidade do sujeito, eram uma prova de que o automatismo ocorreria fora do psiquismo, portanto, no corpo. Apreender o automatismo mental era a possibilidade de isolar o momento muito particular da irrupção da psicose, o ponto de "passagem do psíquico puro, do pensamento abstrato, ao verbal e à sensorialidade das vozes" (Girard, 1993, p. 23). 
Da mesma forma, nas psicoses delirantes, Clérambault procurava isolar os mecanismos geradores dos delírios, constituídos sobre um nó ideoafetivo de base orgânica. Como já dissemos, a Clérambault não interessava mais a provocação da crise, pela produção de fenômenos. Sua intenção era revelar a verdade da posição do sujeito em relação à crença delirante. A ele interessava demonstrar o quanto esta certeza delirante estava funcionando. Procurava, assim, delimitar o ponto de partida do delírio, isolando em meio à argumentação, muitas vezes sistematizada e convincente do paciente, o postulado fundamental, no caso das psicoses passionais, ou, no caso das psicoses interpretativas, uma pseudoconstatação. A exemplo da erotomania, ele a considerava como sendo "em si mesma a psicose", o delírio seria apenas o desenvolvimento do postulado (Clérambault, 2009, p. 313).

Entretanto, isolar e dar visibilidade, seja ao automatismo mental, seja ao postulado fundamental, não era tarefa fácil. Nos casos de erotomania, por exemplo, dada sua reticência natural, o mais frequente era que o paciente negasse explicitamente os seus sentimentos, conseguindo convencer os médicos de que mesmo que seus atos fossem condenáveis, não eram, contudo, motivo para internação. A fim de evitar esse risco, Clérambault orientava seus alunos que não se tratava de procurar os fatos, visto que estes o paciente pode negar sempre. O que se deve buscar é, antes, os pontos de vista do paciente, que estão em fórmulas específicas (p. 286).

De toda forma, quando o paciente não confessava abertamente a sua crença, Clérambault buscava revelá-la a partir de sinais discretos, pois aquilo que o paciente nega explicitamente, ele confessa implicitamente. Procurava assim desvelar o postulado a partir de um sorriso, uma expressão, um olhar, signo desse inconfessável. Em suas palavras: "A esperança surge na credulidade destes doentes, que devemos saber explorar, em suas aquiescências tácitas, em sua animação súbita nesta ou naquela evocação, enfim, nos efeitos mímicos, sempre marcados de hipertônus" (p. 311).

Dessa maneira, no curso de suas apresentações de pacientes era possível acompanhar a obstinação e minúcia com a qual Clérambault procurava atravessar os fenômenos psicóticos para dar visibilidade a seus mecanismos formadores. Deste modo, orientado por esta perspectiva estrutural do sintoma, com seu famoso "olhar de águia", a um só tempo detalhista e minucioso, porém agudo e preciso, Clérambault desenvolveu a arte de extrair a confissão de seus pacientes. Como nos diz Bercherie (2004, p. 11), Clérambault elevou a prática da apresentação de pacientes à perfeição.

É preciso lembrar que para além do rigor clínico e do preciosismo teórico, Clérambault era orientado, em última instância, pela questão da periculosidade. Para estabelecer um diagnóstico, desmascarar uma simulação, reconhecer uma psicose não desencadeada, e fazer um cálculo do risco de passagem ao ato ou de reincidência, Clérambault se norteava por detalhes clínicos que os psiquiatras de hoje, provavelmente, não saberiam nem mesmo identificar. Dessa maneira, interessava-lhe não apenas diferenciar se o comportamento do paciente era efeito de um automatismo mental 


\section{ARTIGOS}

ou de um quadro ideoafetivo, mas dentre as psicoses delirantes, preocupava-se em definir se tratava-se de uma paranoia ou uma psicose passional, pois segundo ele, "o paranoico delira com seu caráter" (2009, p. 291), enquanto no passional "produz-se um nó ideoafetivo inicial, no qual o elemento afetivo é constituído por uma emoção veemente, profunda, destinada a se perpetuar sem cessar, e absorver todas as forças do espírito, desde o primeiro dia"(p. 291). Isso era considerado de fundamental importância para Clérambault, pois como ele dirá: "Diferentes pontos de partida resultam diferenças profundas no tônus psíquico e na extensão do delírio” (p. 292). E mesmo no interior das psicoses passionais, ele ainda procurava discernir suas particularidades. A exemplo da erotomania, a Clérambault importava diferenciar os casos puros dos mistos, visto que isso incidia sobre a evolução e prognóstico do quadro pois, "quanto maior a importância da contribuição imaginativa [caso misto], mais fraca é a contribuição passional [puro]'”(p. 302), o que reflete, por exemplo, na extensão e complexidade do delírio, assim como na intensidade de suas ideias. Reconhecer estes aspectos permitia-lhe avaliar se estas tenderiam a se perpetuar ou se, ao contrário, tendiam a tornar-se difusas e perder a força. Enfim, era essa fineza de detalhes que permitiam a Clérambault avaliar as implicações afetivas do sujeito, consequentemente a intensidade de suas reações, a evolução do quadro e a probabilidade de reincidências.

Para vencer a reticência dos pacientes, tocar os pontos mórbidos e obter todas as informações que precisava, Clérambault (2004) acreditava ser necessário conduzir, muito habilmente, a conversação.

Com um diálogo em aparência difuso mas salpicado de centros de atração para as ideias, devemos conduzir o sujeito a um estado de espírito que o leve a monologar e a discutir; a partir daí nossa tática consistirá em calar-nos ou em contradizer apenas o suficiente para parecermos incapazes de compreendê-lo completamente. Então o sujeito se permitirá expressões que não havia previsto e deixará escapar fórmulas das quais pensa que não prevemos as consequências. (p. 70)

Para tanto, Clérambault (2004) acreditava que era preciso comover o paciente, ativando sua emoção de tal forma que esta escapasse às tentativas do enfermo de ocultá-las. A fim de comover o paciente, ele se utilizava de manobras diferentes em cada caso, o que não poderia ser de outra maneira, pois ele reconhecia que "os casos são por essência individuais" (p. 33). Entretanto, sua necessidade de estabelecer o diagnóstico, associado à sua despreocupação com o tratamento, (até porque ele acreditava que a doença mental era incurável, não se preocupando com as consequências de suas intervenções sobre o paciente), tiveram importante implicação em sua forma de abordagem dos enfermos. Esta posição lhe permitia ir às últimas consequências em suas investigações. Como nos disse Roudinesco (1994), “sem julgá-lo, nem lamentá-lo, mas com uma vontade feroz de extorquir-lhe confissões” (p. 39), Clérambault conseguia arrancar de seus pacientes aquilo que desejava fazer revelar. 
Para conduzir sua exploração minuciosa dos fenômenos e examinar detalhadamente as emoções em causa, Clérambault não hesitava em se utilizar de métodos questionáveis, mesmo condenáveis. Segundo Clérambault, para se obter a confissão, não bastava interrogar o paciente, mas era preciso manipulá-lo. Uma de suas estratégias era, por exemplo, produzir um estado de confiança no paciente, prometendo intermediar no que fosse necessário para ajudá-lo a alcançar suas reivindicações delirantes. Enredando os pacientes nesse estado de confiança, ele os manipulava, provocava, enganava.

Clérambault reconhecia também a importância do público. Inclusive, em seus relatos é possível encontrar algumas referências de como ele se utilizava disso para, nos jogos com seus pacientes, confrontá-los com os personagens de seus delírios. Para ilustrar, tomemos uma apresentação de Clérambault. Trata-se de uma dama francesa, Lea Ana, cujo delírio erotomaníaco se baseava no postulado: "o Rei da Inglaterra me ama". Lea Ana foi conduzida para a Enfermaria Especial, por ter feito escândalo em via pública, e esbofetear dois guardas. No momento de sua admissão, revela, com relativa facilidade, sua convicção delirante. Entretanto, no dia seguinte, quando de sua apresentação pública, na Sociedade Clínica, ela se mostrou reticente tanto sobre os temas de perseguição quanto sobre os erotomaníacos. Contudo, Clérambault (2004) vence sua resistência assegurando à paciente que aquele grupo, diante do qual era apresentada, tratava-se em verdade de um "comitê composto por gente eminente, que teria crédito especial fora da França" (pp. 31-32). Um comitê que se não colocou o Rei em sua presença, foi pelo temor de que ela não se portasse adequadamente, mas que poderia, ainda assim, intermediar seu contato com ele, sendo portadores de uma carta dela para Sua Majestade. Ao prometer intermediar seu contato com o Rei, Clérambault aciona sua esperança, fazendo com que a emoção transbordasse e aparecesse sob sua negação. O sucesso de sua estratégia pode ser comprovado na carta endereçada ao Rei que, ao final da entrevista, Lea Ana entrega a Clérambault (2004):

À Sua Majestade o Rei George V, Rei da Inglaterra.

Majestade: venho solicitar-lhe muito humildemente minha graça e para assegurá-lo de toda minha devoção. A fim de assegurá-lo eu mesma de todo meu afeto e dos sentimentos muito profundos que existem no fundo do meu coração, eu queria pedir a Vossa Majestade uma entrevista que o senhor mesmo marcaria e que me encheria de felicidade. Eu peço do fundo do coração que Vossa Majestade me perdoe e me deixe vir à Inglaterra, onde asseguro a Vossa Majestade de toda minha devoção (pp. 31-32).

Estratégias deste tipo se justificariam pois, como diria Clérambault (2009): "Não se trata com efeito, de saber o que pensa o doente quando está calmo, mas de quais desejos e impulsos é capaz uma vez emocionado, o que vai lhe acontecer, infalivelmente, uma vez que esteja livre" (p. 347). Na ausência deste tipo de manobra, muitas 


\section{ARTIGOS}

enfermas poderiam passar como um estado passional normal, resultando, por exemplo, em "liberações absurdas, seguidas de recidivas imediatas" (p. 330).

E realmente suas intervenções possibilitavam, com efeito, uma grande precisão na definição diagnóstica e consequente acerto nos encaminhamentos. Mas nem isso impediu a polêmica que girou em torno de suas apresentações. Por um lado, a fama de tirânico, arrogante e provocativo, levava a contestações e reações de rechaço, mas por outro lado, seu olhar agudo, penetrante e preciso, fazia de suas apresentações umas das mais requisitadas de sua época.

Assim, as apresentações de Clérambault, o último dos grandes clássicos, foram marcadas pela articulação entre a investigação clínica e o ensino, mantendo a vivacidade e dinamismo que caracterizaram as apresentações dos primeiros tempos. E foram estas apresentações às quais Lacan, aluno de Clérambault, sem dúvida alguma assistiu.

\section{Lacan, aluno de Clérambault}

De certo, que a apresentação realizada por Lacan não é a mesma da psiquiatria. Na medida em que ele foi aspirado pela psicanálise, é deste lugar, enquanto analista, que conduzirá suas apresentações. Se na psiquiatria estas eram operadas a partir dos discursos do mestre, ou universitário, Lacan a toma sob a perspectiva do discurso do analista, o que imprime profundas transformações nessa prática, visto que coloca o paciente enquanto sujeito da palavra, da enunciação.

Contudo, a influência sofrida é explicitada pelo próprio Lacan. Em mais de uma situação, Lacan (1998a) vai se referir a Clérambault como tendo sido seu "único mestre em psiquiatria" (p. 65). Lacan reconhece, inclusive, que não obstante a concepção organicista deste, é a Clérambault que ele devia sua concepção estrutural e psicogênica da loucura. E de fato, é possível percebermos que o caráter autônomo e parasitário com o qual Clérambault define o automatismo mental, coincide justamente com a definição que Lacan dá da psicose à época do $O$ seminário. Livro 3. As psicoses (1955-1956/1992), sobre as psicoses enquanto efeito de uma intrusão da estrutura significante. Sobre isso Lacan dirá: "seu automatismo mental, com sua ideologia mecanicista de metáfora, por certo bastante criticável, parece-nos, em seus enfoques do texto subjetivo, mais próximo do que se pode construir de uma análise estrutural do que qualquer esforço clínico na psiquiatria francesa" (p. 69).

No que diz respeito à apresentação de pacientes, podemos ver que Lacan não apenas deu continuidade, mas soube desenvolver a acuidade clínica do mestre. Assim como Clérambault, Lacan perpetuou o seu interesse agudo e penetrante que buscava, para além dos fenômenos, a posição do doente. Afinal, será este mesmo elemento mínimo, formador, estrutural, que Clérambault buscava revelar nas suas apresentações, que ganhará destaque 
nas apresentações de Lacan. Assim como seu mestre, a intenção de Lacan era buscar, para além dos fenômenos psicóticos, o "nó central do caso" (Laurent, 1989, p. 165), não obstante esse nó central tivesse conotações diferentes para cada um. Para Clérambault o centro de seu interesse era desvelar o automatismo mental nas psicoses alucinatórias crônicas e o postulado, no caso das psicoses passionais. Já Lacan, pelo menos no primeiro momento de seu ensino, vai tomar como centro de seu interesse o fenômeno elementar, revelador da posição do sujeito em sua relação com o Outro da linguagem.

Quando dizemos que em suas apresentações, Lacan buscava a posição do sujeito, isso implica dizer que, embora possamos encontrar alguns pontos indicativos de sua filiação a Clérambault, e portanto dizer que, em última instância, suas apresentações tiveram origem no interrogatório clássico, contudo haverá diferenças fundamentais entre elas.

Como ponto comum, temos, sobretudo, a manutenção do caráter clínico, investigativo, abandonado pela perspectiva psiquiátrica "biologicista" — hegemônica na época de Lacan. No que diz respeito especificamente a Clérambault, podemos ressaltar a precisão e acuidade das intervenções, que visavam não o fenômeno, mas a posição do paciente.

Contudo, as apresentações de Lacan irão se diferir imensamente de seus antecessores, no que diz respeito às suas estratégias de intervenção. Em verdade, ao operar o dispositivo da apresentação de pacientes sob a lógica do discurso do analista, Lacan subverte profundamente o sentido e alcance desta prática. Ao visar o sujeito, Lacan eleva a investigação a outra dimensão. Enquanto os clássicos, Clérambault entre eles, se restringiam à dimensão imaginária do Eu, no eixo a-a', Lacan vai se interessar pela dimensão inconsciente, deslocando assim o interesse do enunciado para a enunciação. Portanto, não se trata mais de desmascarar o paciente, mas fazer emergir o sujeito enquanto tal.

Para pensarmos esses pontos de convergência e de divergência entre as apresentações de Clérambault e de Lacan, tomaremos um dos fragmentos de apresentações realizadas por Lacan e comentados por ele, em $O$ seminário. Livro 3. As psicoses (1955-1956/1992), quando faz referência à dificuldade de se acessar o sujeito. Como nos dirá Éric Laurent (1995), o sujeito psicótico não tem necessariamente vontade de nos falar daquilo que lhe interessa: "É preciso dispô-lo a isso. Se ele não estiver disposto, não se conseguirá nada. Não se conseguirá nada de essencial, ou seja, ele se manterá na fala comum" (p. 122). Para tanto, os psiquiatras clássicos confrontavam o paciente, provocando a crise. Já Clérambault, como vimos, procurava ativar a emoção de forma que esta escapasse das tentativas do enfermo de ocultar-se pela racionalização. Quanto a Lacan, ele convidava o paciente a falar.

Isso é o que nos revela Lacan, ao relatar uma de suas apresentações: tratava-se de uma moça que vivia uma folie a deux com a mãe. Ela não se mostrara muito disposta à apresentação (como conjectura Lacan, provavelmente por já ter participado de outras apresentações antes desta). Lacan avalia que foi "certa doçura", que ele havia posto na aproximação da moça, o que favoreceu o bom entendimento entre eles, dispondo-a 


\section{ARTIGOS}

a sair da fala comum. É assim que a paciente lhe confia que uma pessoa tão gentil, tão boa quanto ela própria, tinha sido vítima de atos hostis. Revela que, certo dia, ao cruzar com o amante da vizinha no corredor, este lhe dissera um palavrão. Após certa reticência, visto que tal termo a depreciava, ela acaba por confessar: "Ele disse Porca." Evidencia-se assim que a paciente alucina.

Entretanto, é preciso marcar que esse "Porca" não foi entregue facilmente, mas veio como efeito da intervenção de Lacan. Se ele chegou a vencer a reticência da paciente e capturar esse fenômeno, como ele irá esclarecer, foi justamente por não compreender. Podemos ver aqui, algo de sua filiação à Clérambault, contudo, há entre o não compreender de Lacan e de Clérambault, uma diferença fundamental. Retomemos o dito de Clérambault, de que era preciso "parecermos" incapazes de compreender o paciente. Chamamos a atenção, aqui, para o "parecer" — afinal, ele acreditava que era possível saber "tudo" sobre o paciente, sobre sua doença. Aliás, acreditava que era possível saber até mais que o paciente, e era sustentado nesse saber a mais, que ele operava suas manobras de manipulação (Clérambault, 2004) para produzir a comoção no doente.

Quanto a Lacan, a estratégia era não compreender, de fato. A compreensão faz com que o analista se detenha, que não prossiga na investigação, pois já compreendeu. Ao compreender, o analista estaria entrando no jogo do paciente, colaborando com sua resistência, "reforçando a tentativa inconsciente do paciente de dissimular o que está em causa em sua fala" (Leguil, 1998, p. 93). Para o analista, ao contrário, "o que se trata de compreender é precisamente porque há alguma coisa que é dada [pelo paciente] para ser compreendida" (Lacan, 1992, p. 60).

O que podemos perceber é como Lacan não se perde no engodo da compreensão. Se Lacan chega a dispor a paciente a sair da fala comum, se extrai algo fundamental nessa entrevista, é justamente porque, ao não compreender, ele permite que o sujeito emirja, aproximando-se assim do centro da questão. Dessa forma, para alcançar a alucinação "Porca", ele não precisou desestabilizar a paciente, produzindo uma crise a partir de sua confrontação, como fariam os clássicos, nem mesmo manipulá-la, comovê-la de forma a ativar sua emoção, como faria Clérambault. Muito atento às nuances do discurso do paciente, o que Lacan (1998b) fez foi se interessar em saber "o que nela mesmo poderia ter se proferido no instante anterior [à injúria]" (p. 540). Em lugar de se endereçar ao Eu imaginário, Lacan visa o sujeito, implicando-o. É assim que a paciente, “com um sorriso de concessão", lhe confessa "que não era naquele ponto completamente inocente, pois ela própria tinha dito alguma coisa ao passar". E foi somente após revelar sua própria fala: "Eu venho do salsicheiro" que, na sequência, ela, espontaneamente, revela a vivência alucinatória: "Porca" (Lacan, 1992, pp. 59-60).

Sobre esse precioso achado, Lacan (1998b) irá nos dizer que: "semelhante descoberta só pode dar-se à custa de uma submissão completa, ainda que advertida, 
às posições propriamente subjetivas do doente" (p. 540). Considerando, como nos diz Porge (2009), que submeter-se à posição subjetiva, submeter-se ao sujeito, é "submeter-se às surpresas da linguagem, às síncopes da enunciação. Quando elas aparecem, pode-se dizer que o sujeito se apresentou, sem que seja bem localizável no nível das pessoas (...)” (p. 226). Eis então que o grande achado de Lacan não é a confissão de que a paciente alucina, como interessaria aos clássicos. Tampouco a presentificação do mecanismo gerador da psicose, como classificaria Clérambault, revelando a presença do automatismo mental. O achado de Lacan é mais interessante - o que ele desvela, é a posição do sujeito como objeto de gozo do Outro, ou seja, a posição estrutural do sujeito psicótico.

Deslocar o interesse do fenômeno, para o sujeito, teve importantes consequências sobre essa prática. Ainda que as apresentações fossem extremamente ricas, desde o ponto de vista semiológico, o interesse de Lacan estava para além da demonstração de fenômenos. Em lugar de se utilizar do discurso do mestre, em suas apresentações, Lacan vai operar a partir do discurso do analista. Isso implica dizer que a perspectiva clínica de Lacan se difere da perspectiva clássica, pois seu interesse está para além da preocupação com o diagnóstico e o prognóstico. A aposta radical na virtude da palavra para mudar a clínica de um caso elevou para primeiro plano a preocupação terapêutica, preocupação, inclusive, inexistente nas apresentações de Clérambault. Em última instância, podemos propor que, em suas apresentações, o que Lacan procurava eram os indícios da posição de gozo do sujeito, indicativos fundamentais para a direção do tratamento.

\section{Lacan, para além do mestre}

Não obstante as diferenças que o percurso de Lacan irá imprimir em sua perspectiva teórica e prática em relação ao mestre, é interessante observar como Clérambault preparou "a filigrana, ou a topologia daquilo que Lacan apontará como sujeito" (Viganò, 1997, p. 43). É o que podemos ver, por exemplo, no caso da alucinação verbal "Porca". Este teria, tanto para Clérambault quanto para Lacan, um valor clínico paradigmático, visto que a intrusão do significante, de forma parasitária, estrangeira, com que este se impunha independente da intencionalidade da consciência, indicaria para ambos uma falha estrutural. A diferença fundamental, mas de extraordinárias consequências clínicas, é que essa dualidade passividade-invasão seria, para Clérambault, uma prova de sua origem orgânica, enquanto, para Lacan, tal fenômeno revelaria a posição do sujeito enquanto objeto de gozo do Outro.

Contudo, é preciso reconhecer que Clérambault levou as investigações da organicidade da doença mental aos limites do psiquismo. Talvez não seja por acaso 


\section{ARTIGOS}

que tenha sido Lacan, justamente um discípulo de Clérambault, o último grande psiquiatra clássico, quem levou às últimas consequências a aposta na causalidade psíquica das psicoses, fundando, no que diz respeito a essa estrutura, uma nova perspectiva clínica.

\section{Referências}

Bercherie, P. (2004) Presentación. In G. G. de Clérambault, Automatismo mental: paranoia (pp. 9-24). Buenos Aires: Polemos.

Clérambault, G. G. de (2004). Automatismo mental: paranoia. Buenos Aires: Polemos. (Trabalho original publicado em 1942).

Clérambault, G. G. de (2009). Os delírios passionais. Erotomania, reivindicação, ciúme. In M. T. Berlinck, \& G. E. Berrios (Orgs.), Erotomania (pp. 285-289). São Paulo: Escuta. (Trabalho original publicado em 1921).

Clérambault, G. G. de \& Lamache (2009). Erotomania pura persistente há 37 anos. In M. T. Berlinck, \& G. E. Berrios (Orgs.), Erotomania (pp. 343-351). São Paulo: Escuta. (Trabalho original publicado em 1923).

Ferreira, C. (2006). Apresentação de pacientes: (re)descobrindo a dimensão clínica. Dissertação de Mestrado, Universidade Federal de Minas Gerais, Belo Horizonte.

Ferreira, C. (2013). Apresentação de pacientes: dispositivo e discursos. Tese de doutorado, Universidade Federal de Minas Gerais, Belo Horizonte.

Foucault, M. (2006). O poder psiquiátrico. Curso dado no Collège de France (1973-1974). São Paulo: Martins Fontes.

Girard, M. (1993). Gaëtan Gatian de Clérambault: fragmentos escogidos para un recorrido histórico. In P. Moron, M. Girard, H. Maurel, \& S. Tisseron. Clérambault maestro de Lacan (pp. 9-62). Buenos Aires: Nueva Visión.

Lacan, J. (1992). O seminário. Livro 3. As psicoses - 1955-1956. Rio de Janeiro: Jorge Zahar.

Lacan, J. (1998a). De nossos antecedentes. In: J. Lacan, Escritos (pp. 69-76). Rio de Janeiro: Jorge Zahar.

Lacan, J. (1998b). De uma questão preliminar a todo tratamento possível da psicose (19571958). In J. Lacan. Escritos (pp. 537-590). Rio de Janeiro: Jorge Zahar.

Laurent, E. (1989). A apresentação de pacientes. Clínica Lacaniana, Publicação de Psicanálise da Biblioteca Freudiana, 3, 149-187.

Laurent, E. (1995). A disciplina da entrevista com o sujeito psicótico. In E. Laurent, Versões da clínica psicanalítica (pp. 121-126). Rio de Janeiro: Jorge Zahar.

Leguil, F. (1998). Sobre as apresentações clínicas de Jacques Lacan. In F. Leguil, Lacan, você conhece? (pp. 92-99). São Paulo: Cultura. 
Porge, E. (2009). Apresentação de paciente: uma clínica da apresentação. In E. Porge, Transmitir a clínica psicanalítica: Freud, Lacan, hoje (pp. 223-235). Campinas: Ed. Unicamp.

Roudinesco, E. (1994). Jacques Lacan: esboço de uma vida, história de um sistema de pensamento. São Paulo: Companhia das Letras.

Viganò, C. (1997). De Clérambault e a lógica do sujeito. In: C. Viganò. Saúde mental: psiquiatria e psicanálise (pp. 36-47). Belo Horizonte: Instituto de Saúde Mental, Associação Mineira de Psiquiatria.

\section{Resumos}

(Presentations of pacients: Clérambault, teacher of Lacan)

The presentation of patients is a traditional device in psychiatry and was introduced into psychoanalysis by Lacan. This article analyzes the influences that Lacan received from his master, Clérambault, highlighting the points of continuity and the changes produced in the practice of presentation, based on its operation through the discourse of the analyst.

Key words: Presentation of patient, psychoanalysis, Lacan, Clérambault

(La Pésentation des patients: Clérambault, maître de Lacan)

La présentation des patients est un dispositif traditionnel de la psychiatrie qui a été introduit en psychanalyse par Lacan. Cet article analyse l'influence de Clérambault sur Lacan, son élève, en soulignant les points de continuité et les changements qui se produisent dans la pratique de la présentation à partir de sa réalisation par le discours de l'analyste.

Mots clés: Présentation des patients, psychanalyse, Lacan, Clérambault

(La presentación de pacientes: Clérambault, maestro de Lacan)

La presentación de pacientes es un dispositivo tradicional de la psiquiatría, que se introdujo en el psicoanálisis de Lacan. Este artículo analiza las influencias que Lacan recibió de su maestro, Clérambault, destacando los puntos de continuidad y los cambios producidos en la práctica de la presentación de pacientes operados por el discurso del analista.

Palabras clave: Presentación del paciente, psicoanálisis, Lacan, Clérambault

(Vorstellung von Patienten: Clérambault, Lacans Meister)

Die Vorstellung von Patienten ist ein traditionelles Mittel der Psychiatrie, das von Lacan in die Psychoanalyse eingeführt wurde. In diesem Beitrag werden die Einflüsse von 


\section{ARTIGOS}

Clérambault, Lacans Meister, auf ihn untersucht, wobei die Kontinuitätsaspekte und die hervorgerufenen Veränderungen in der Umsetzung der Vorstellung hervorgehoben werden, ausgehend von ihrer Wirkung durch den Diskurs des Analysten.

Schlüsselwörter: Vorstellung der Patienten, Psychoanalyse, Lacan, Clérambault

Citação/Citation: Ferreira, C. M. R. \& Santiago, J. (2014, junho). Apresentação de pacientes: Clérambault, mestre de Lacan. Revista Latinoamericana de Psicopatologia Fundamental, 17(1), 204-217.

Editor do artigo/Editor: Manoel Tosta Berlinck

Recebido/Received: 15.8.2013/8.15.2013 Aceito/Accepted: 12.10.2013 / 10.12.2013

Copyright: (C) 2009 Associação Universitária de Pesquisa em Psicopatologia Fundamental/ University Association for Research in Fundamental Psychopathology. Este é um artigo de livre acesso, que permite uso irrestrito, distribuição e reprodução em qualquer meio, desde que o autor e a fonte sejam citados / This is an open-access article, which permits unrestricted use, distribution, and reproduction in any medium, provided the original authors and sources are credited.

Financiamento/Funding: Os autores declaram não ter sido financiados ou apoiados/ The authors have no support or funding to report.

Conflito de interesses/Conflict of interest: Os autores declaram que não há conflito de interesses / The authors declare that has no conflict of interest.

\section{Cristiana Miranda Ramos Ferreira}

Doutorado em Psicanálise pela Universidade Federal de Minas Gerais - UFMG (Belo Horizonte, MG, Br); Professora de Psicopatologia na FEAD (Belo Horizonte, MG, Br).

Av. do Contorno, 4023/1107 - Funcionários

30110-021 Belo Horizonte, MG, Br

e-mail: cris.ramos.bhz@gmail.com

\section{Jésus Santiago}

Doutorado pela Universidade de Paris VIII (Paris, Fr); Professor de Psicopatologia e Psicanálise na Universidade Federal de Minas Gerais - UFMG (Belo Horizonte, MG, Br).

Av. do Contorno 5351/808 - Funcionários

30110-035 Belo Horizonte, MG, Br

e-mail: santiago.bhe@terra.com.br 